How to Cite

Kalpana, R. (2018). Teaching principles of clear writing through activities for tertiary level learners. International Journal of

Social Sciences, 1(1), 42-46. https://doi.org/10.31295/ijss.v1n1.16

\title{
Teaching Principles of Clear Writing through Activities for Tertiary Level Learners
}

\author{
R. Kalpana \\ PSG College of Technology, Coimbatore, Tamil Nadu, India \\ Email: kalpana.ranganathan@gmail.com
}

\begin{abstract}
This article looks at teaching principles of clear writing to tertiary level learners using activities. While the general lecture method uses the lecture mode of teaching which caters only to the auditory learners, most other learners (the VAK) are left behind. This paper attempts to weave certain activities into a writing lesson in order to make the lesson more rich, enjoyable and enriching

Keywords---activities, carousel, running dictation, teaching writing, VAK learners.
\end{abstract}

\section{Introduction}

Teaching writing is generally considered to be a monotonous task and more so with college learners, who have neither the will nor the inclination to put their pens to paper. This issue is all the more relevant in the modern times, where smartphones have taken over the world over, coupled with the multiple other distractions the learners are subject to on any given day. Given these circumstances, any direct instruction on writing is hardly capable of holding the attention spans of the tertiary level college learners. More specifically, direct instruction on the principles of clear writing, which lays the foundation for any document they spin at their levels, is a prerequisite to teaching writing.

A cursory glance at the writing requirements of any engineering student would reveal that engineering learners would be required to draft the following documents at their collegiate and professional levels

Table 1

Collegiate and professional levels

\begin{tabular}{ll}
\hline College level Requirements & Professional/workplace requirements \\
\hline & Memos \\
1.Writing reports & Emails \\
2.Leave/apology letters & Technical documents such as descriptions, \\
3.Term papers and assignments & definitions, and instructions \\
& Business letters \\
\hline
\end{tabular}

Though the form of these documents is different, the essential principles of writing define the underlying characteristics features of any kind of writing point towards mastering the fundamental principles of writing. This understanding of principles would ensure that these are adhered to in their real life writing.

The textbooks for engineering learners at the first year level at the authors' workplace contains a unit on the "Principles of Clear writing" which focuses on the following principles of clear writing - coordination and subordination, appropriate use of connectives, giving end focus, parallelism, consistency in tone, tense, and voice. One of the most convenient and the generally adopted method of teaching these principles is the omnipotent, inevitable "lecture method". Though this is not a method to be dispensed with, it is also for practitioners to understand this caters largely to the auditory learners. Also, while this method could be effective in the case of subjects like history, it can hardly be effective in the case of acquiring skills related to language. This is further 
compounded by the fact that any classroom has a heterogeneous set of learners whose learning styles vary from the visual, auditory to the kinaesthetic Hence, the effectiveness of this method is highly questionable and is doubtful of cultivating $\mathrm{r}$ higher-order cognitive and attitudinal goals (Cashin 1985; Day 1980; Frederick 1999; Renner 1993). Further, the lecture method, during which most learners tend to listen passively to the teacher, hardly offers scope for other types of learners such as the visual, kinesthetic and other types of learners to be actively involved in the process of learning.

\section{Research Method}

Fortunately, the author had the opportunity of attending some of the Cambridge teacher support programmes for the BEC examinations offered by Cambridge during which, the certain interesting activities that would cater to learners with different learning style were demonstrated. During the programme, these activities were used for introducing sub skills of language, practicing them, consolidating and reviewing the same some of the most significant and interesting features of these activities observed by the authors who participated as trainees include

a) A right mix of activities catering to learners with different learning styles

b) Integrated skills approach VS discrete skills

c) The right mix of starters and settlers to set the class in motion

d) Scope of peer learning and feedback

e) Scope for individual work, pair work, and group work

It was decided to adapt and use these activities for teaching writing in the author's classroom context to help learners learn and practice a few principles. Some of the activities introduced into the lesson include gallery walk, Clap, and stamp, carousel brainstorming, four corners, board rotation. The entire description of these activities is given below:

\section{Results and Analysis}

\section{Connectives through reordering strips and clap and stamp (whole class activity)}

Five sentences containing different connectives were chosen and each part of the sentence was given as given as individual strips to the learners chosen at random. These learners were called to the front of the class and to hold the strips of cards out so that the cards were visible to the entire class. These strips were of course not in a sequence, resembling the sample given below
Is
it interesting
messy
but is

The remaining learners who were seated were requested to make meaningful sentences (politics is interesting but it is messy, in the given example for instance) and they were found to interact with one another until they came to a consensus. This activity involves the visual style learners and was also found to offer immense scope for peer interaction, wherein to the surprise of the authors, even the reticent learners came forward to volunteer answers or at least talk to their partners about the possible combinations. In order to emphasize the importance of connectives and to consolidate the learners understanding of connectives, the teacher tried to blank out the connective at the end of the activity to check with learners if the sentence still made sense without the use of these connectors.

\section{Coordination and subordination through carousel brainstorming (group activity)}

After giving a brief preview of the elements of coordination and subordination, the entire class was divided into 5 groups. To begin with, each group discusses their ideas on Subordination and Coordination and puts them on charts both subordination and coordination. After a specific time, say 3-4 minutes, this group then passes on the sheet to the group to its right, who then are required read, reflect, discuss and add one example sentence each for both coordination and subordination. This group passes the chart on to its right again, who in turn add their example sentences. This process was continued till the groups get back the original sheets they started off with. The skills practiced include reading, reading and speaking.

Clap and stamp were used to review their understanding of the principles of sand $\mathrm{S}$ where they would clap. The teacher would read a sentence and the learners were required to clap their feet if it happens to be subordination and stamp their feet if it is subordination. 


\section{End focus on finding the partner activity (whole class activity)}

Sentences containing end focus were split into two halves and distributed at random to each student. Some of the samples include

What is more important is // how one does it

What concerns us the least is // how to do it

The most important things in life are //taxes and money

The learners were requested to find their partners to make meaningful sentences with the focus at the end of these sentence. Yet again, the learners were required to complete this activity within a specific time.

\section{Teaching modifiers through onion ring activity}

The class is asked to form two circles, one inner circle and one outer circle and the learners in the inner circle were given strips containing specific nouns/verbs (e.g. rains/rained ) a, while those in the outer circle were given the corresponding modifying adjectives and adverbs - all at random. When the teacher rings the bell, each student in the inner circle read out their strips to the student that s/he faces. After the inner circle student finishes, the outer circle student reads out the strip and they check to discuss if the strips they could be a possible combination of adjectives and noun. When the teacher rang the bell, only the student in outer circle moved one step to the right, so that they have another partner this time. The activity is continued till all of them found their rightful combinations. Once this is a whole class activity and the skills practiced include reading, and speaking.

\section{Redundancies \\ Running dictation activity for review and consolidation}

Review activity was done using a running dictation activity wherein each group is given the sentence containing principles of end focus, coordination and subordination, using modifiers etc. in table given below and the explanation of that principle

\begin{tabular}{ll}
\hline $\begin{array}{l}\text { He walked slowly but } \\
\text { sturdily }\end{array}$ & $\begin{array}{l}\text { Two sentences of } \\
\text { equal rank joined } \\
\text { together } \\
\text { One clause depends } \\
\text { on he walked } \\
\text { slow, he walked } \\
\text { sturdily }\end{array}$ \\
$\begin{array}{l}\text { What matters is if one } \\
\text { makes it }\end{array}$ & $\begin{array}{l}\text { The most emphatic } \\
\text { idea is at the end of } \\
\text { the sentence }\end{array}$ \\
\hline
\end{tabular}

The actual principles (coordination, subordination, end focus, using modifiers) were stuck in strips of papers so that they are not immediately visible. Once again, the learners were regrouped and each group chooses a runner who runs to read one principle and comes back to dictate the same to the group while the remaining members decide where they fit in each containing a principle is embedded and the other members of the group read it out to the student, The learners in each group take turns to be the runner and to figure out the sentence that matches the description. The team that completed it first was declared as the winning group.

\section{Conclusion}

One of the most interesting aspects of this lesson is that it is a definite break from the tedium of lectures, both for the teacher and the learners. Secondly, these activities promote more mobility and interaction in the classroom. Since all types of learners have a chance to participate in the activities, it is sure to promote a richer and meaningful learning experience. However, it is important to ensure that the teacher keeps the spirit of competition alive by strictly timing each round of activities. Also, it is important for the teacher to be prepared for a bit of clerical work beforehand. Preparing strips using different colors could be a boring job.Most importantly, it is important for the 
teacher to give proper instructions and follow them up with instruction checking questions after briefing the class about the activity. If these points are adhered to, then teaching writing can certainly be an interesting job.

\section{Acknowledgements}

The author would like to thank the editor for their valuable time and advice. 


\section{References}

Astawa, I. N., Mantra, I. B. N., \& Widiastuti, I. A. M. S. (2017). Developing Communicative English Language Tests for Tourism Vocational High School Students. International Journal of Social Sciences and Humanities (IJSSH), 1(2), 58-64.

Cashin, W. E. (1985). Improving lectures. Kansas State University.

Chávez, S. A. R., \& Quijije, K. K. B. (2018). A Challenge for Teachers of Inclusive Higher Education. International Research Journal of Management, IT and Social Sciences (IRJMIS), 5(2), 129-135.

Ginaya, G., Rejeki, I. N. M., \& Astuti, N. N. S. (2018). The effects of blended learning to students' speaking ability. International Journal of Linguistics, Literature and Culture (IJLLC), 4(3), 1-14.

Maba, W., \& Mantra, I. B. N. (2017). An Analysis of Assessment Models Employed by The Indonesian Elementary School Teachers. International Journal of Social Sciences and Humanities (IJSSH), 1(1), 39-45.

Mandala, H. (2018). Divergent Principles of Politeness in Verbal and Non-Verbal Directive Speech Act. International Research Journal of Engineering, IT and Scientific Research (IRJEIS), 4(2), 41-51.

Pescosolido, B., \& Aminzade, R. (Eds.). (1999). The social worlds of higher education: Handbook for teaching in a new century (Vol. 2). Pine Forge Press.

Renner, P. (1993). The art of teaching adults. Training Associates: Vancouver, British Columbia.

Suparsa, I. N., Mantra, I. B. N., \& Widiastuti, I. A. M. S. (2017). Developing Learning Methods of Indonesian as a Foreign Language. International Journal of Social Sciences and Humanities (IJSSH), 1(2), 51-57. 